Sains Malaysiana 47(9)(2018): 2187-2194

http://dx.doi.org/10.17576/jsm-2018-4709-29

\title{
Malaysian Household Income Distribution: A Fractal Point of View
}

(Taburan Pendapatan Isi Rumah Malaysia: Suatu Sudut Pandang Fraktal)

\author{
FATIMAH ABDUL RAZAK* \& FARIDATULAZNA AHMAD SHAHABUDDIN
}

\section{ABSTRACT}

Malaysian Household Income Survey data provided by the Malaysian Department of Statistics is used to provide evidence that the upper tails of the household income distribution follows a fractal based distribution known as power-law. Inequality measures are then applied to ascertain the levels of inequality based on this distribution. In addition to that, we analyzed the data in terms of different classes of occupation, obtained power-law exponents for each class and then highlighted the inequality between these classes.

Keywords: Fractals; household income distribution; inverted Pareto coefficient; Pareto inequality; power-laws

\section{ABSTRAK}

Data daripada Tinjauan Pendapatan Isi Rumah Malaysia yang diperoleh daripada Jabatan Perangkaan Malaysia digunakan untuk menentusahkan bahagian hujung atas taburan pendapatan isi rumah mengikuti taburan berasaskan fraktal yang dikenali sebagai 'power-law'. Kemudian, beberapa ukuran ketaksamaan digunakan untuk memberikan gambaran tahap ketaksamaan pendapatan rakyat Malaysia. Seterusnya, analisis ini juga dijalankan ke atas kelas pekerjaan yang berbeza.

Kata kunci: Fraktal; ketaksamaan Pareto; pekali Pareto sonsang; 'power-law'; taburan pendapatan isi rumah

\section{INTRODUCTION}

The main economic indicator of a country's growth is usually taken to be the Gross Domestic Product (GDP). GDP can be roughly defined as the total market value of all goods and services produced in a certain country in a given period of time (Ivkovic 2016). GDP mainly mirrors the product of a country, regardless of the type of product and who benefits from it. One of the main criticisms of GDP is the fact that it does not take into account the distribution of wealth resulting from these production. More often than not, the extra income generated by the growth in production is enjoyed only by a small portion of the population often referred to as the privileged elite. In light of this, we seek to understand more about the Malaysian economics through analyzing the distribution of Malaysian Household Income and particularly the top $10 \%$.

The top earners are usually the ones benefiting the most from increases in GDP especially in English speaking countries (Atkinson et al. 2011). This is sometimes attributed to improvement in talent allocation, leading to more overall profits and hopes that the wealth will spill over to the rest of the population. On the other hand, the unequal distribution of wealth may lead to resentment in the less endowed portion of society. This resentment has been touted as the underlying cause to political upheavals in many countries. Thus, the recent focus on the bottom $40 \%$ (B40) of the population by the government of Malaysia is seen as a step in the right direction. Without getting into the long winded debate of the left versus right approach to economy, this paper intends to shed some light on the level of income inequality in Malaysia by scrutinizing the top $10 \%$ of its earners, in an attempt to further illuminate its path towards a stable and strong economy.

\section{THE FRACTAL NATURE OF ECONOMICS}

First introduced by Mandelbrot, fractals can be described as never-ending patterns that are self-similar across different scales (Takayasu \& Takayasu 2010). These patterns can sometimes occur due to repeated application of relatively simple operations and can be found abundantly in nature. From the simple repeated pattern of a fern leaf to the branching pattern of river networks observed from satellites, people have been finding fractals everywhere.

This is particularly true for economics since Mandelbrot himself was said to have envisioned the concept of fractals while he was analyzing the price fluctuation of the New York cotton market (Mandelbrot 1963) using the daily data of more than a hundred years. He was struck by the geometrical similarity between charts of different time scales and envisioned that scale invariance in both shape and distribution could also be true for other natural occurrences. Scale invariance is a feature that remains unchanged at different scales of a variable (such as time in Mandelbrot's case). This feature is at the heart of the fractal. A fractal can be roughly defined as a complicated scale-invariant configuration (Takayasu \& Takayasu 2010). 
Therefore, if a shape of a fractal can be observed geometrically, zooming in on the fractal will reveal the same patterns repeated over and over again regardless of the scale one is zooming at. Think about zooming in on the repeated patterns of a fern leaf or a Romanesco broccoli. However fractals can also be shapeless quantities, in which case it is characterized by its distribution known as the power-law (or scale free) distribution (Ogwang 2011; Takayasu \& Takayasu 2010). A fractal is said to be scale free due to its scale-invariance (self-similarity) in this sense.

The probability distribution of variable representing a fractal can be written as

$$
P(X \geq x) \propto x^{-\alpha}
$$

where $\alpha>0$ is a constant known as the power-law exponent (Clauset et al. 2009; Newman 2010). This distribution is also sometimes referred to the as the Pareto law (distribution) for top incomes (Atkinson et al. 2011; Brezinski 2014; Mandelbrot 1963) especially when wealth allocation is concerned. Thus is also known as the Pareto parameter. Pareto's work suggested that the upper tails of income and wealth distributions follows a power-law and this has been observed in varying degrees for incomes of many different countries such as the US, China, Russia (Brezinski 2014), Canada (Ogwang 2011), India (Sinha 2006), Australia, Italy (Clementi et al. 2006) as well as many other countries (Atkinson et al. 2011). The rich-getsricher concept usually observed in income distributions leads to the fractal nature of it (Jones 2015).

One of the most important works on economic equality was done by the late British economist, Sir Anthony Barnes Atkinson. His group at Oxford University has collected, analyzed and shared their findings on 25 different countries including Malaysia. His Chart book of Economic Inequality is very informative and have plots of data ranging from before independence (1957) up till 2014 (Atkinson et al. 2017). The data they analyzed are taxation data including the ones kept by the British before independence. Unfortunately, on that same page, under the 'Wealth Inequality' and 'Dispersions of Earnings' one will find that 'no suitable data were found' is written (retrieved 31 March 2018).

The aim of this paper was therefore threefold. First we provide evidence that the top income bracket of the Malaysian household income follows a power-law. Next, using the exponent of the power-law extracted from the data and by some rough comparison with exponents of other countries, we then attempt to understand the level of relative inequality throughout the years 2007 - 2014 . Subsequently, we illustrate that the level of inequality is different for different types of job-classification. Despite the many pitfalls of power-law estimation (Brzezinski 2014; Clauset et al. 2009), we believe that the analysis will provide valuable insights into the economic standing of Malaysia.

\section{INCOME DISTRIBUTION AND THE TOP 10\%}

The 2007 - 2014 Household Income and Basic Amenities Surveys (HIS) was provided by the Malaysian Department of Statistics (DOS). Based on the DOS report, the average Malaysian household has around four members with two breadwinners and there are more households with multiple income recipients than there are single-income households (Department of Statistics Malaysia 2014).

Table 1 summarizes the basic statistical indicators of the data where one can see that all the values are increasing throughout the years except for the value of maximum income that drops to about 1.2 million ringgits in 2009 from the previous 1.3 million in 2007. According to the World Bank, Malaysia's GDP from 2007 to 2014 was always on the rise except for the year 2009 where the GDP dropped due to recession. Therefore, this indicates that the GDP of the country is highly dependent on the high income earners earning close to the maximum value.

A higher increase is observed from 2012 to 2014 as compared to the increase in previous years. The differences in income distribution is widening as evident from the maximum and minimum income especially from 2012 to 2014 . The median income in 2014 is RM51,020 whereby $50 \%$ of the population has less than this value. The maximum household income is about RM2.24 milion for 2014 and the gap between the income of the average population and the top earners seems to be larger in 2014 compared to 2012. The same data is plotted in Figure 1 and it is clear that most Malaysians are in the lower half of the income bracket. In fact, the median household income is often used in the Malaysian context (Intan Nadia et al. 2016) since the mean does not reflect the income of most households due to distortion by the incomes of the upper income bracket.

In Figure 2, we take the log-log plot of values in Figure 1. One can see that towards the right hand side of

TABLE 1. Basic statistics of Malaysian Household Gross Income (Ringgit Malaysia)

\begin{tabular}{lcccc}
\hline Summary & 2007 & 2009 & 2012 & 2014 \\
\hline Minimum & 710 & 1200 & 1800 & 2550 \\
Maximum & 1308000 & 1225000 & 1272000 & 2243000 \\
Median & 26330 & 30860 & 38650 & 51020 \\
Mean & 38630 & 43760 & 53760 & 68960 \\
Std.Dev & 43282.27 & 44864.88 & 58108.13 & 69791.53 \\
\hline
\end{tabular}




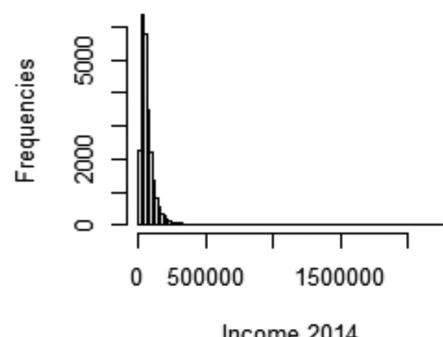

Income 2014

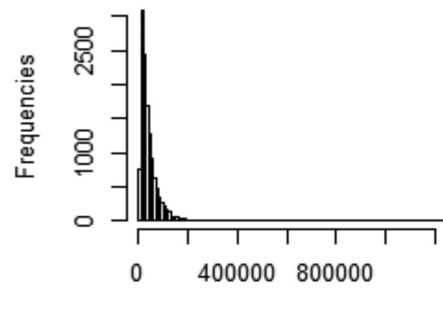

Income 2009
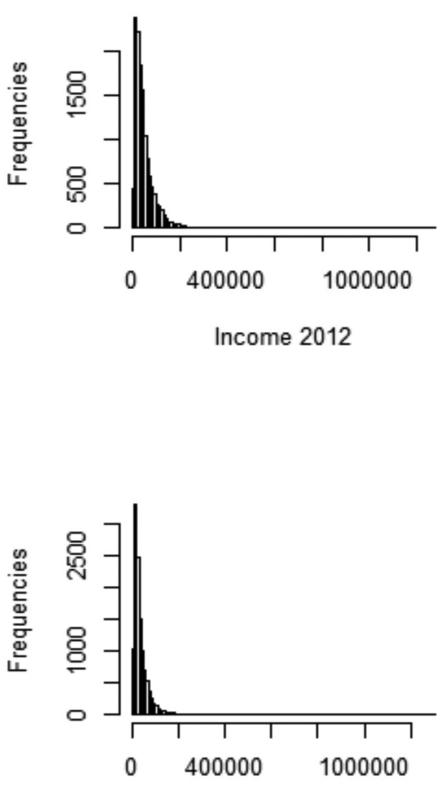

Income 2007

FIGURE 1. Malaysian Household Gross Income Distribution for years 2007 - 2014
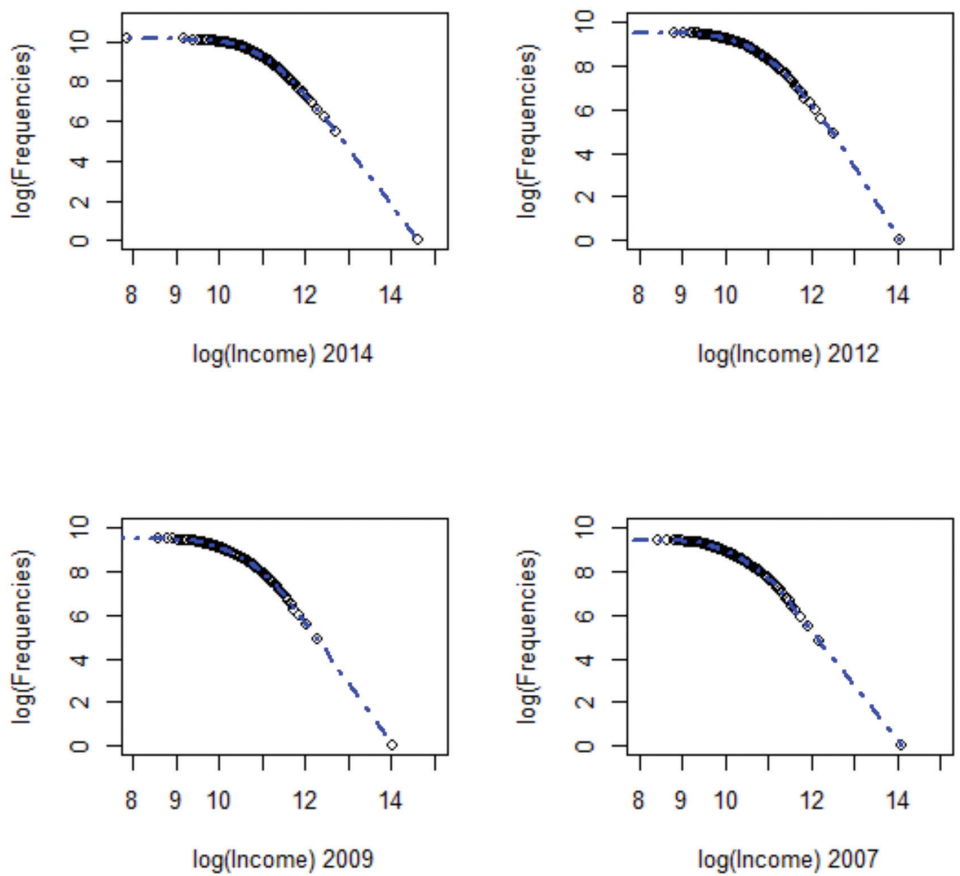

FIGURE 2. Log Income vs log frequencies of the Malaysian Household Gross Income Distribution for years 2007 - 2014

the graph (top income bracket) things start to look very linear. We shall argue that this is evidence indicating a fractal nature of the data. In Figures 3 and 4, we plotted the top $10 \%, 1 \%$ and $0.1 \%$ of the gross household income for years 2014, 2012, 2009 and 2007. One can see that the figures of straight line look quite similar regardless of the scale $(10 \%, 1 \%$ and $0.1 \%)$ with values of between 2.5 and 3 (save for one occurrence of $0.1 \%$ in 2012 which we attribute to the lack of data). The combined top $10 \%$ for all four years is plotted in Figure 5, leading one to conclude that the exponent fluctuates between 2.5 and 2.75. Thus we observe the power-law distribution in the top $10 \%$ of the data of all four years in which the survey was done.

\section{QUANTIFYING INEQUALITY}

To relate the values in Figure 5 with level of inequalities, there are several indicators that can be utilized (Atkinson et al. 2011). The relationship between the level of 


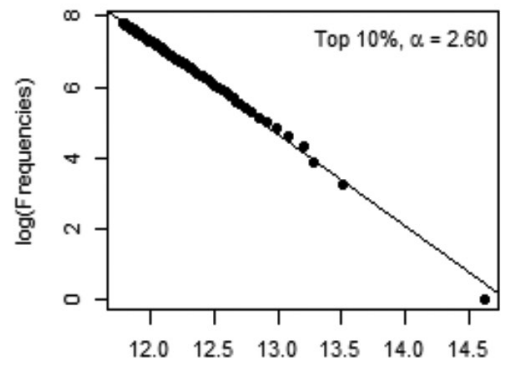

$\log ($ Income) 2014

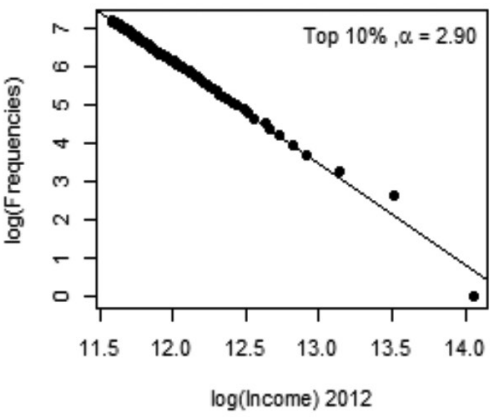

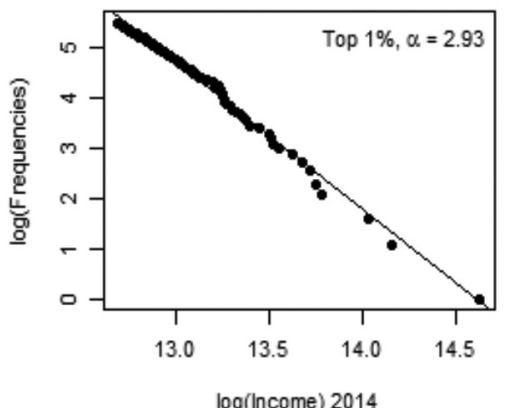
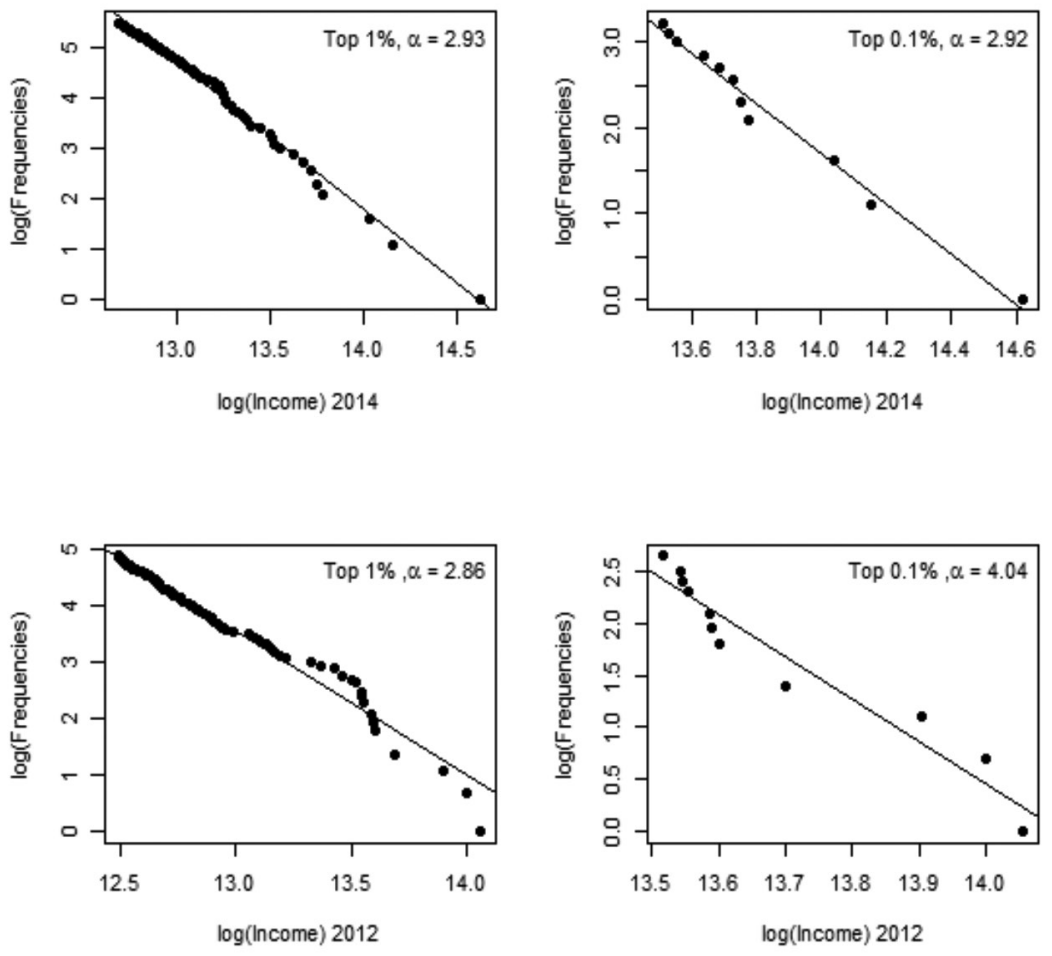

FIGURE 3. Plot of Top 10\%, 1\% and 0.1\% values of the Household Income for years 2014 and 2012
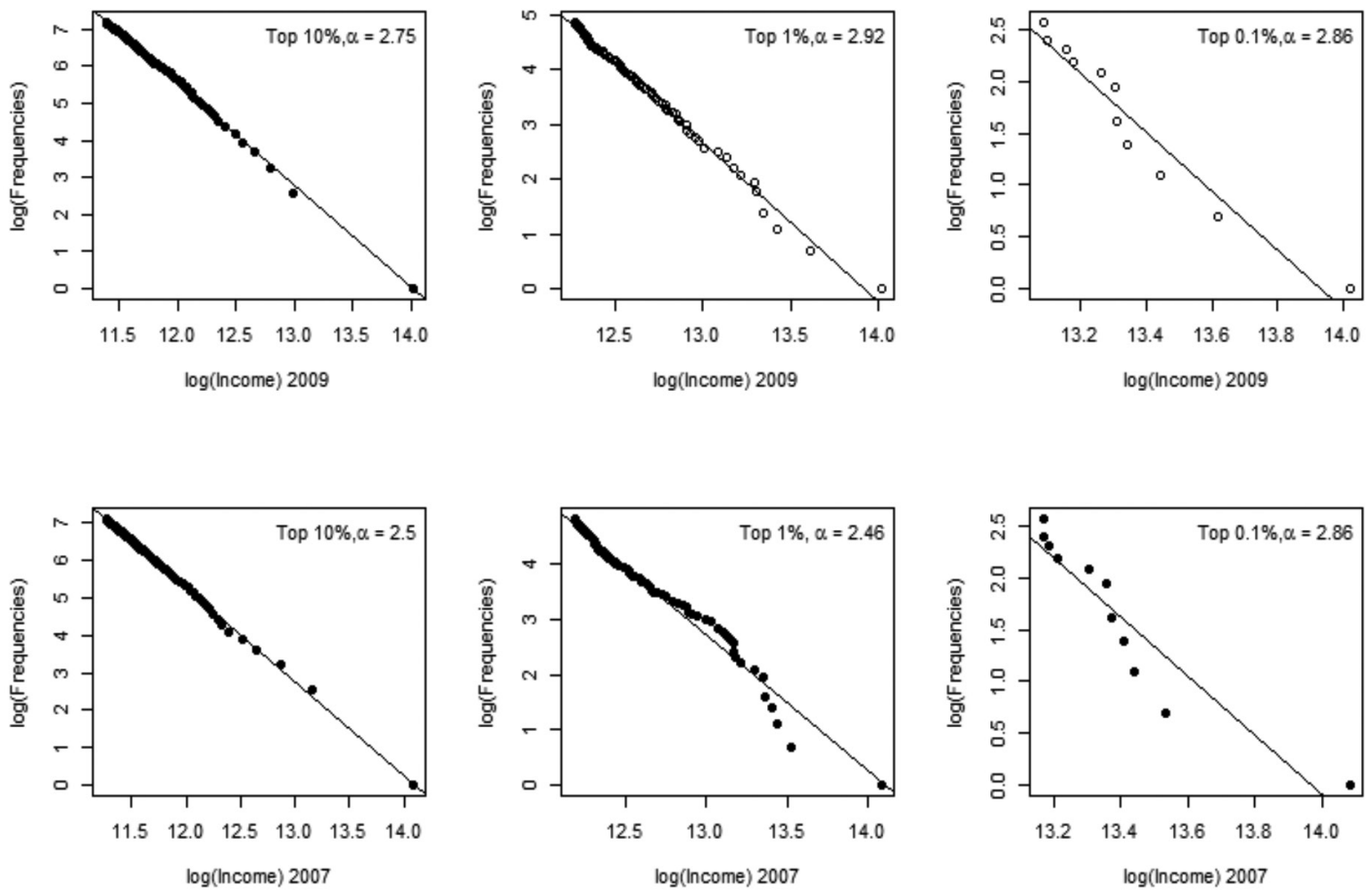

FIGURE 4. Plot of Top 10\%, 1\% and 0.1\% values of the Household Income for years 2009 and 2007

inequality and exponent is generally taken to be inversely proportional. In fact, a simple form of inequality indicator known as the Pareto Inequality (Jones 2015) can be written for variable such that,

$$
P(X \geq x) \propto x^{\frac{1}{n}} .
$$

Thus when we compare (2) to (1), we get that $\alpha=$ $1 / \eta$. The larger value of , the larger the level of inequality. 


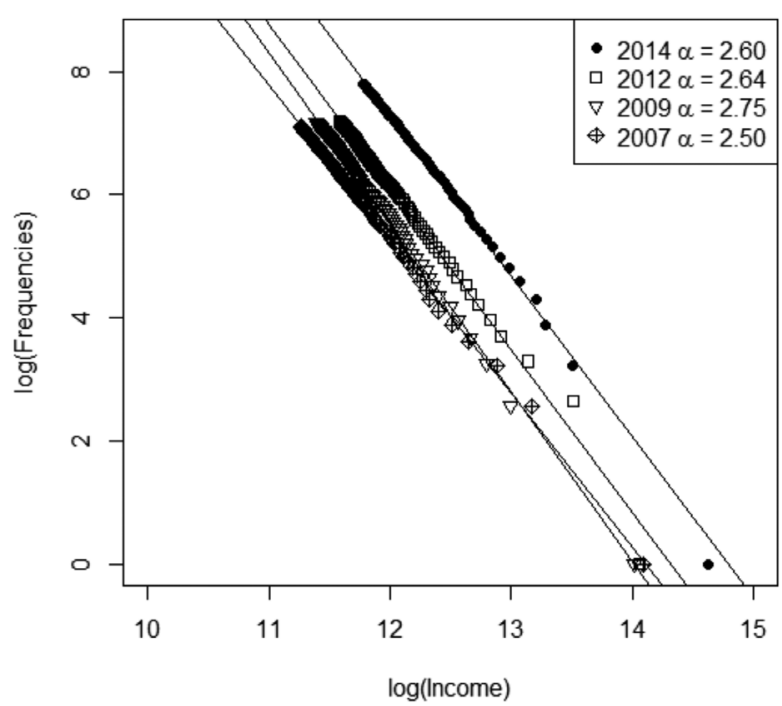

FIGURE 5 . Values of $\alpha$, for the Top $10 \%$ Household Income for 2007 - 2014

TABLE 2. Values of $\boldsymbol{\alpha}$ for Top $10 \%, 1 \%$ and $0.1 \%$ for year 2007 - 2014

\begin{tabular}{cccc}
\hline Year & Top 10\% & Top 1\% & Top 0.1\% \\
\hline 2014 & 2.60 & 2.93 & 2.92 \\
2012 & 2.64 & 2.57 & 4.04 \\
2009 & 2.75 & 2.92 & 2.86 \\
2007 & 2.50 & 2.46 & 2.86 \\
\hline
\end{tabular}

Therefore, smaller values of indicates higher inequality. Looking back at Figure 5, one can observe that except for the year 2009 (in which GDP decreased), the Malaysian value of $\alpha$ is generally decreasing. From this point of view, one can say that from the year 2009 onwards (after the recession), the general level of inequality of the top $10 \%$ is increasing.

To illustrate the meaning of this statement even further, we utilize the inverted Pareto coefficient $\beta$ (Atkinson et al. 2011) which is derived from the power-law exponent such that $\beta=\frac{\alpha}{\alpha-1}$. The values $\alpha$ and $\beta$ has an inversely proportional relationship since $\beta=\frac{\alpha}{\alpha-1}=\frac{1+\alpha-1}{\alpha-1}=\frac{\alpha}{\alpha-1}+1$, however it has a more intuitive description of inequality. For example, $\beta=$ 2 will imply that the average income of individuals with income above 100,000 is 200,000 and the average income of individuals with income above 1 million is 2 million. This due to the fractal (self-repeating) nature of the distribution. $\beta$ has also been used to indicate the 'fatness' of the upper tails in Pareto distribution.
Taking the 2014 value for $\alpha=2.6$ from Figure 5, we get that $\beta=1.625$. Thus implying that those with income above the RM2018955 income threshold (the lower bound for the top 10\% obtained from Table 1) earn (RM2018955) $\beta=$ RM3280802 on average. As displayed in Table 3, the top $10 \%$ is earning on average 3.28 million as compared to just 1.84 million in 2012, 1.73 million in 2009 and 1.96 million in 2007. This result tallies with claims of widening income inequality in Malaysia (Atkinson 2013; Krongkaew \& Ragayah 2006).

To put things in a more international perspective, take into account the calculated Pareto Inequality $\eta=0.6$ (thus $\beta=2.5$ ) for the United States of America (Jones 2015). From Table 3, the 2014 values for Malaysia are $\alpha=2.6$ $\eta=0.38$ and $\beta=1.625$. Therefore in this way, one can say that, the level of inequality in the USA is higher than Malaysia. Different values of $\alpha$ have been approximated for many different countries (Atkinson et al. 2011). For example, approximations of the values for the year 2000 for Australia, Italy (Clementi et al. 2006) and South Korea (Yoon \& Kim 2005) are 2.3, 2.5 and 3, respectively. Taking into account Malaysia's $\alpha=2.5$ in 2007, one can roughly say that Malaysia's inequality level (of the top earners) in 2007 is rather similar to South Korea's and Italy's in the year 2000, while being more equal than Australia at the time.

\section{JOB TYPES AND INCOME DISTRIBUTION}

Furthermore, we also analyzed the data separately for different occupation types. The occupation category follows the MASCO 2008 classification (MASCO2008, 2010). The power-law obtained from the top $10 \%$ of each occupation category is displayed in Table 4 . In the table, the 'Managers' category has $\alpha=4.74, \eta=0.21$ and $\beta=$ 1.27. However, the 'Plant and Machine-Operators and Assemblers' category has $\alpha=4.74, \eta=0.21$ and $\beta=$ 1.27 . Thus, we can conclude that income inequality is generally higher for managers compared to operators and assemblers. All the other categories are in between these two in terms of inequality, sorted from highest to lowest inequality in Table 4.

Based on Figure 6,66.4\% of the top 10\% of household income earners in 2014 are from jobs categorised as 'Technicians \& Associate Professionals' as well as 'Professionals'. Surprisingly clerical support workers contribute to $14.34 \%$ of the top $10 \%$ income earners in 2014. Even though 'Managers' are only $1.5 \%$ of the top $10 \%$ income earners in Figure 6, their average income is the highest among all classes. A more thorough analysis

TABLE 3. Values for Top 10\%, 1\% and $0.1 \%$ for year $2007-2014$

\begin{tabular}{ccccc}
\hline Year & $\alpha$ & $\eta$ & $\beta$ & Average income of Top 10\% (RM) \\
\hline 2014 & 2.60 & 0.3846 & 1.625 & 3280802 \\
2012 & 2.64 & 0.3788 & 1.6097 & 1843139 \\
2009 & 2.75 & 0.3636 & 1.5714 & 1732689 \\
2007 & 2.50 & 0.4 & 1.6667 & 1962118 \\
\hline
\end{tabular}


TABLE 4. Values of $\boldsymbol{\alpha}, \eta$ and for Top $10 \%$ of Household Income 2014 divided by categories of occupation

\begin{tabular}{lccc}
\hline Occupations categories & $\alpha$ & $\eta$ & $\beta$ \\
\hline Managers & 2.66 & 0.38 & 1.60 \\
Occupations not elsewhere classified & 2.78 & 0.36 & 1.56 \\
Professionals & 3.11 & 0.32 & 1.47 \\
Technicians and associate professionals & 3.24 & 0.31 & 1.45 \\
Service and sales workers & 3.24 & 0.31 & 1.45 \\
Elementary occupations & 3.27 & 0.31 & 1.44 \\
Skilled agricultural, forestry and fishery workers & 3.45 & 0.29 & 1.41 \\
Clerical support workers & 3.89 & 0.26 & 1.35 \\
Craft and related trades workers & 3.92 & 0.26 & 1.34 \\
Plant and machine-operators and assemblers & 4.74 & 0.21 & 1.27 \\
\hline
\end{tabular}

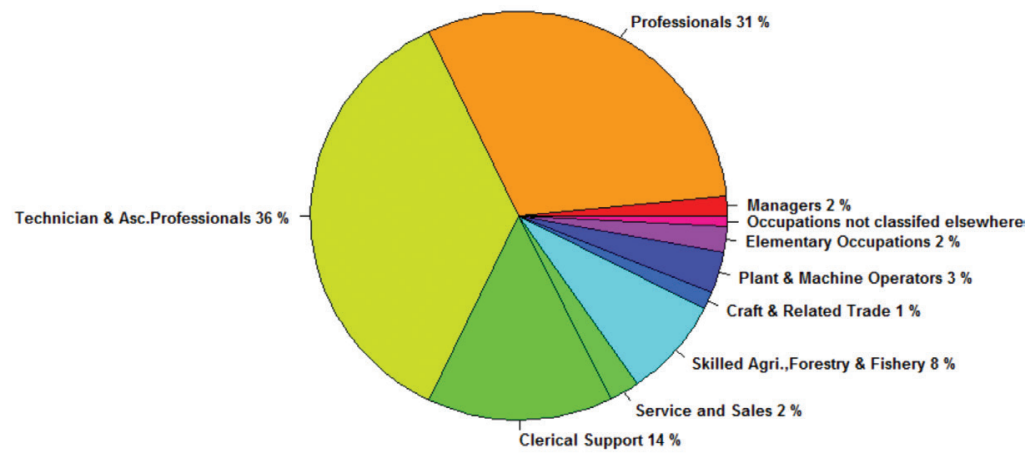

FIGURE 6. Pie chart of job categories for the Top 10\% of Household Income 2014

of the income of these job types throughout the different years is the subject of future research.

\section{DISCUSSION}

The advent of big data has fostered interdisciplinary interactions of many different fields of studies including mathematics, physics and economics with the common aim of understanding the nature of data sets. One such interdisciplinary area is called econophysics with fractals as one of its founding elements (Takayasu \& Takayasu 2010). Economics and wealth distribution are very important issues especially with the emergence of the internet and hence the various channels to voice out resentment for people feeling left out despite the growth in GDP.

The power-law exponents used to understand the level of inequality given by the survey has shown that alongside this increase in GDP comes the increase in income inequality. As previously demonstrated, this inequality is a long way from the levels in the USA, however our results indicate that it is increasing more rapidly than in previous years. We view this result as significant since a domestic economy like Malaysia needs disposable income to fuel consumption (Khazanah Research Institute 2014) thus income inequality may reduce the pace and durability of economic growth. Over the last thirty five years, the inequality level have increased substantially in English speaking countries, India and China but not in continental European countries or Japan (Atkinson et al. 2011). This increase is highly suspected to be due to the surge in top wages.

From Table 4 and Figure 6, one can see that the top $10 \%$ of the 'Managers' has the most unequal salary range but they comprise only $1.5 \%$ of the top $10 \%$ overall income earners even though their average income is the highest. Therefore it is not too farfetched to say that the increase in the level of inequality was highly influenced by wage increases in this category. This is also a factor in many other countries (Atkinson et al. 2011) where the CEOs and top management getting paid exorbitantly high salaries has come under scrutiny. Being a developing country, Malaysia is already grappling with these issues (for example the recent focus of the government to the bottom $40 \%$ ) and research into wealth inequality is of paramount importance.

Prof Atkinson and his group have derived the Malaysian values of for the top $1 \%$ up till 2010 by analyzing taxation data (Atkinson 2013). However from 1997 to 2010 only the values of for the top 0.5 in the top $1 \%$ is given. For years 2007 to 2010 the value of hovers between 2.2 and 2.4. This is a more detailed analysis that can be done with a larger amount data and higher frequency, which is not the case with the current data in our possession as evident from Figures 3 and 4 where the top $0.1 \%$ leaves only a few data points to be extrapolated 
from. Our results in Table 3, which gives the value of for the top $10 \%$ in the same time period is much less accurate.

Nevertheless, we are very thankful to the Department of Statistics for the survey data used in this research. Regardless of doubts in terms of its accuracy (Atkinson 2013), it gives us valuable insights into the general Malaysian income distribution. For future research we are hoping to get more accurate and higher frequency data. This will enable us, to do a more detailed comparison with other countries in terms of top $1 \%$ or even top $0.01 \%$ of the population.

On a more local level, arguably the most sensitive issue in Malaysia is the income inequality between the races. The New Economic Policy of 1971 is said to be successful in lowering wealth inequality (Krongkaew \& Ragayah 2006) although the numerical evidence when examined as a whole country is scant (Atkinson 2013). We suspect that analyzing the income inequality along the racial line may be able to shed some light on the issue. It will also be interesting to see the effect of the recent focus of the government to the bottom $40 \%$ (B40) and its effect on the level of inequality as a whole country, separate states and along racial lines.

\section{CONCLUSION}

In this preliminary research, we provide evidence that the upper tails of the Malaysian Gross Income Distribution follows a power-law thus fractal in nature. We then utilized Pareto Inequality and the inverted Pareto coefficient to form inequality indicators from the power-law exponents. The outcome of this simple analysis confirms the general increase in level of inequality. Furthermore, when the same data is divided into different occupation categories, we found that the 'Manager' category forms $1.5 \%$ of the top $10 \%$ of earners. However, the 'Manager' category has the smallest exponent value indicating the highest inequality amongst its top $10 \%$ and it also has the highest average income amongst all categories. This highlights the need for more scrutiny in terms of different categories of the society, especially the 'Manager' category, to identify the main sources of inequality. It is our hope that this research will contribute towards the strengthening of Malaysia's current economic position.

\section{ACKNOWLEDGEMENTS}

We would like to thank the Malaysian Department of Statistics for providing the surveys and members of the Takayasu Lab (Misako in particular) of Tokyo Institute of Technology for the helpful ideas, discussions and motivation. We are grateful for the grants FRGS/1/2015/ SG04/UKM/02/1 and GP-K015732 for funding our research and visit to Takayasu Lab.

\section{REFERENCES}

Atkinson, A.B., Hasell, J., Morelli, S. \& Roser, M. 2017. Chartbook of economic inequality. https://www. chartbookofeconomicinequality.com/.

Atkinson, A.B., Piketty, T. \& Saez, E. 2011. Top incomes in the long run of history. Journal of Economic Literature 49(1): 3-71.

Atkinson, A.B. 2013. Top Incomes in Malaysia 1947 to the Present (With a Note on the Straits Settlements 1916 to 1921). WTID Methodological Note. http://wid.world/document/ wid_methodology_notes_2013_5_malaysia/.

Brzezinski, M. 2014. Do wealth distributions follow power laws? Evidence from 'rich lists. Physica A. 406: 155-162.

Clauset, A., Shalizi, C.R. \& Newman, M.E. 2009. Power-law distributions in empirical data. SIAM Review 51(4): 661-703.

Clementi, F., Di Matteo, T. \& Gallegati, M. 2006. The power-law tail exponent of income distributions. Physica A 370: 49-53.

Department of Statistic Malaysia. 2014. Household Income and Basic Amenities Report. https://newss.statistics.gov. my/newss-portalx/ep/epFreeDownloadContentSearch. seam?cid $=45687$

Intan Nadia Jalil, Muhammed Abdul Khalid, Yap Gin Bee, Jarud Romadan Khalidi, Nazihah Muhamad Noor, Tan Theng Theng \& Adibah Abdulhadi. 2016. The State of Households II, Kuala Lumpur: Khazanah Research Institute.

Ivkovic, A.F. 2016. Limitations of the GDP as a measure of progress and well-being. Ekonomski vjesnik/EconviewsReview of Contemporary Business, Entrepreneurship and Economic Issues 29(1): 257-272.

Jones, C.I. 2015. Pareto and Piketty: The macroeconomics of top income and wealth inequality. Journal of Economic Perspectives 29(1): 29-46.

Khazanah Research Institute. 2014. The State of Households. Kuala Lumpur: Khazanah Research Institute.

Krongkaew, M. \& Ragayah, M.Z. 2006. Income distribution and sustainable economic development in East Asia: A comparative analysis. http://www.networkideas.org/feathm/ oct2006/PDF/Medhi_Krongkaew_Ragayah_Haji.pdf.

Malaysia Standard Classification of Occupations 2008 (Masco2008). 3rd ed. 2010. Ministry of Human Resources Malaysia. http://static.jobsmalaysia.gov.my/html/jobsm/ masco/en/MASCO_BI_master.pdf.

Mandelbrot, B.B. $196 \overline{3}$. The variation of certain speculative prices. The Journal of Business 36: 394-419.

Newman, M. 2010. Networks: An Introduction. New York: Oxford University Press, Inc.

Ogwang, T. 2011. Power laws in top wealth distributions: Evidence from Canada. Empir. Econ. 41: 473-486.

Sinha, S. 2006. Evidence for power-law tail of the wealth distribution in India. Physica A 359: 555-562.

Takayasu, M. \& Takayasu, H. 2010. Fractals and Economics. Chapter 10. In Complex Systems in Finance and Econometrics, Selected entries from the Encyclopedia of Complexity and Systems Science. 2-vol. set, edited by Meyers, R.A. New York: Springer-Verlag. pp. 444-463.

Yoon, S.M. \& Kim, K.S. 2005. Distributions of Korean household incomes. Journal of the Korean Physical Society 46(4): 1037-1039. 
Pusat Pengajian Sains Matematik

Fakulti Sains dan Teknologi

Universiti Kebangsaan Malaysia

43600 UKM Bangi, Selangor Darul Ehsan

Malaysia
*Corresponding author; email: fatima84@ukm.edu.my

Received: 21 September 2017

Accepted: 30 April 2018 